\title{
A Study of Seismograph Setup in Schools to Educate and Awareness Programme for Students
}

\author{
Satish Saha*, R Vijaya Raghavan, ANS Sarma, G Suresh, A Sateesh, \\ PR Jitendar and D Srinagesh \\ CSIR-National Geophysical Research Institute, Uppal Road, Hyderabad-500007, India
}

\begin{abstract}
In this article efforts have been made to describe how education and awareness programme on seismograph setup helps the school students to learn more about the occurrence of earthquakes and safety measures to be adopted during the earthquake. Soon after the Bhuj earthquake of January 26, 2001, a mission mode project in seismology was initiated by the Government of India with a view to create new scientific and technology $(S \& T)$ base and appropriate human resources for mitigating the adverse impact of earthquake hazard. Ministry of Earthquake Sciences (MoES), Government of India has sponsored this project to CSIRNational Geophysical Research Institute (NGRI), Hyderabad to setup 80 broadband educational seismographs in secondary schools in the earthquake prone region of Western Maharashtra. A educational seismograph setup in secondary school campus creates interest among schools students to know more about a felt earthquake in the area or destructive teleseismic earthquakes. The schools teachers shall be trained on operation of seismograph, seismic data retrieval, analysis and locating the earthquakes. The trained teachers disseminate this knowledge to the school students year after year. It also aims at motivating scientists for spreading knowledge beyond the boundaries of their institutions to create awareness among the students.

Keywords: Earthquakes, Educational, Seismograph, Seismogram and Broad-band Seismometer.
\end{abstract}

\section{Introduction}

Earthquakes are natural phenomenon, which occur all of a sudden without any warning sometimes resulting in loss of lives and property. Significant part of our population lives under a threat of damaging earthquakes particularly in high seismic zone like Himalayas, Gujarat and Northeast India. The Himalayan Tectonic belt is constantly generating active stresses not only along Himalayan zone but also in its neighboring regions. The periodic accumulation of stress is being released in various segments resulting in earthquakes. Moderate to large earthquakes occur in our country in Himalayan region as well as Peninsular India. The Koyna (1967), Kilari (1993), Bhuj (2001) and Kashmir (2005) earthquakes are testimony to the great loss of human life and property. The awareness about the science of earthquakes, earthquake safety measures and disaster mitigation among the people residing in the earthquake prone area is less in a developing country like India. In order to create such awareness, it is appropriate to start such program at the schools level targeting young students. Capturing the innate curiosity of students for natural phenomenon like earthquakes and transforming the enthusiasm into a meaningful learning experience is a great challenge for a science teacher. The teacher has to be equipped with adequate resources and training for this task. The schools were selected based on various factors such that location of schools nears the active seismic zone, school infrastructure and number of students etc. A suitable room at each school was selected for the installation of educational seismograph. Immediately, site preparation work including the construction of seismic pit, etc was taken up. Out of the total eighty (80) educational seismograph locations, thirty (30) seismographs are equipped with single component seismogram and fifty (50) seismographs with 3-Component Seismogram comprising data acquisition system, data storage facility, desktop computer and data processing software. The goal for the educational Seismograph setup among secondary school students is centered on creating fruitful linkages between research institutions and secondary schools; engaging students in acquisition of seismological data to help teachers to bring the applicability of science in classroom.

\section{Seismicity of Western Maharashtra}

Koyna-Warna region in South Western Maharashtra surrounded by the districts of Satara, Sangli, Kolhapur, Ratnagiri and Raigad districts is seismically active region of Peninsular shield of India. After the impoundment of Koyna dam, this region witnessed an earthquake of magnitude 6.3 on December 10, 1967 claiming 200 people lives. The region experiences continued seismic activity for more than four decades since then. It comes under zone IV of seismic zoning map (Bureau of Indian Standards, 2002). The earthquakes occurring in this region is being felt not only in the above districts but also as far as Pune and Mumbai. Several organizations including CSIR-NGRI have been monitoring the seismic activity in this region. The purpose of 
this project in the Western Maharashtra is the protracted seismicity in Koyna-Warna region for more than four decades.

Killari is another region in Maharashtra that was rocked by a moderate earthquake of magnitude 6.3 in the early morning of September 30, 1993. The Killari earthquake is the deadliest Stable Continent Region earthquake in the recorded history killing more than 7500 people and causing huge damage to property in 17 villages in Latur and Osmanabad districts.

\section{Objectives of Programme}

1. To setup seismograph in selected secondary schools of the earthquake prone regions of Maharashtra. Educate students about earthquakes i.e. earthquake recording, analysis, creation of database and maintaining seismic station and earthquake safety. The philosophy of this project is to teach students while they do experiments.

2. To develop a network of resource persons for disseminating the knowledge to teachers and students about the science of earthquakes and seismometers and application of mathematics, physics in earth sciences. Demonstration of earthquake mechanism through lectures, audiovisual aids.

3. To operate and maintain a low cost seismic network and generate data useful in evaluating the seismicity of the region.

4. To disseminate information to teachers and students about earthquakes and Mitigation of seismic hazard.

Under this programme, eighty (80) schools were selected for setup of educational seismograph in Western part of Maharashtra including eight districts such as Kolhapur, Satara, Ratnagiri, Sangli, Raigad, Nanded, Latur and Osmanabad. Fig. 1 shows the locations of educational seismograph installation in schools of Western Maharashtra.

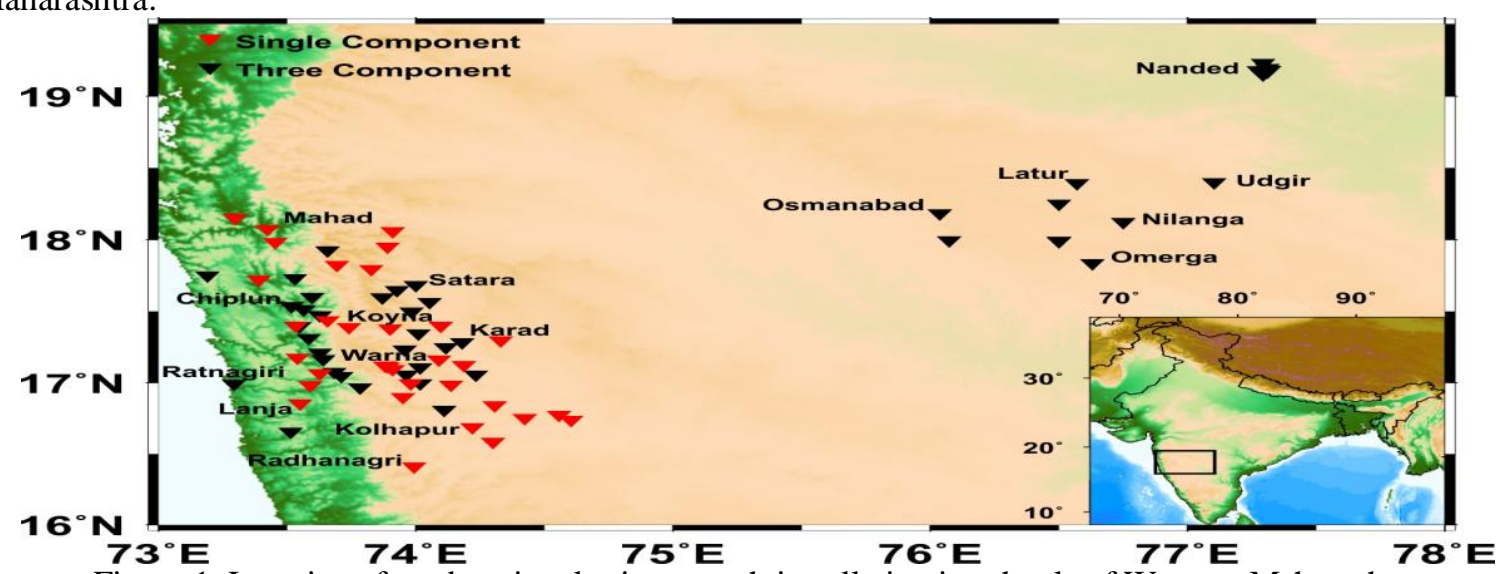

Figure 1. Locations for educational seismograph installation in schools of Western Maharashtra

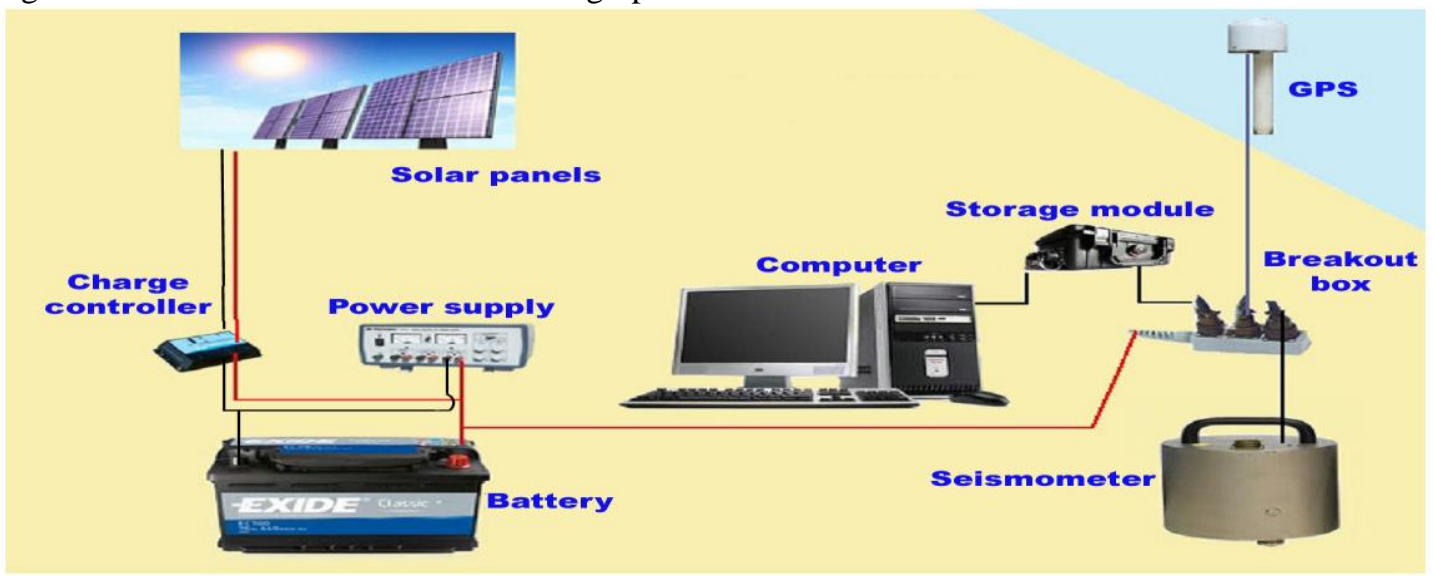

figure 2. Block diagram of educational seismograph setup

The educational seismograph setup is equipped with a broad-band seismometer. Fig.2 shows the block diagram of seismograph setup in schools of western Maharashtra with three components broad-band seismometer CMGEDU with a digitizer and a recorder. The CMG-EDU is a low version educational seismometer, which has an electromagnetic transducer that converts the ground motion into electrical signals as soon as it is powered up. The CMG-EDU is the Sensitive instrument designed to measure extremely small movements of the ground with a sensitivity of $2000 \mathrm{~V} / \mathrm{m} / \mathrm{s}$ in the frequency range 0.033 to $50 \mathrm{~Hz}$. The seismometer can record local, regional 
and distant earthquakes and the ground motion due to surf on nearby beaches, quarry blasts, heavy machinery, traffic and even people moving around the sensor. The data acquisition system (DAS) have many advantages like low power consumption, more compact, lighter in weight, requires less maintenance than other recorders. The DAS is a 3 channel, 24-bit Broad-band Seismic recorder with an output rate of 100 samples per second. The DAS is based on a high-resolution sigma-delta ADC converter and produced high quality seismic data suitable for all kinds of investigation [1]. The seismic data recorded by DAS is locally stored in the USB flash disk available up to 16 GB capacity. Data from the flash disk may be read by swapping and connecting to any personal computer/Workstation using USB ports. Data can also be remotely downloaded from the DAS disk using FTP over LAN/WAN. The Guralp system GPS receiver provided with the CMG-EDU is rugged and $100 \%$ water proof unit capable of providing accurate GPS time to a resolution better than 100 microseconds. It uses the standard NMEA protocol, and also provides longitude and latitude information. The GPS receiver is connected to the digitizer with a single cable, which carries both data and power. The CMG-EDU is a low cost seismograph suitable for educational purpose. It is required to operate the seismograph on $24 \mathrm{X} 7$ bases as earthquakes can occur any time of the day. Hence it is powered by DC $12 \mathrm{~V} \times 100 \mathrm{AH}$ lead acid battery of two numbers in each station as AC power may not be available uninterrupted. The batteries are charged by solar power as well as AC-DC chargers. Each earthquake lab has $2 \times 75$ Watt solar panel for charging batrteries.Not only is the hardware optimized for field deployments, software tools have been specially developed to support both field and base station operation.

\section{Construction of Seismic Pit}

A seismometer pit of the (4-feet length, 4-feet width and 3-feet depth) was constructed in the selected room [3]. A concrete pier of 2 feet by 2 feet with a sidewall of 9-inch thickness was also constructed to install the seismometer as shown in Fig. 3.

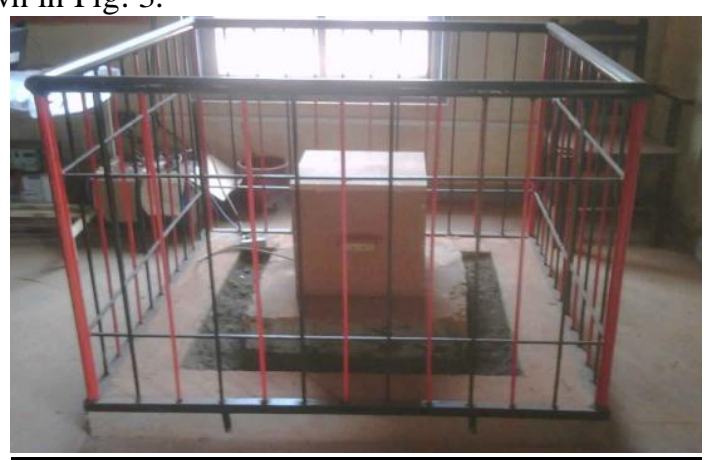

Figure 3. Seismometer pit with the broad-band seismograph covered with an insulated box

\section{Data Analysis}

Data generated by these earthquake laboratories has been used for education, awareness and research purpose. In the earthquake lab, Picking $\mathrm{P}$ and $\mathrm{S}$ phase arrivals, computing the epicentral distance, and locating the events on a map are the popular exercises [4]. This is similar to science lab experiment where a student learns by doing experiments. Single component seismogram of local earthquake of magnitude 2.0 occurred on February 21, 2011 in Koyna region recorded at Chikli seismograph station shown in Fig. 4 along with phase picks "EPg", "ESg" and "Coda" length (duration of the earthquake) in seconds help in finding the local magnitude $\left(\mathrm{M}_{\mathrm{L}}\right)$ of the earthquake. 3-Components seismogram of local earthquake of magnitude 2.1 occurred on October 22, 2013 in Kilari region of Maharashtra also recorded at Nilanga seismograph station as shown in Fig. 5.

Magnitude Calculation: For finding the magnitude, pick coda (coda is the end point of the recorded earthquake) and measure the coda in seconds from p- time. Now refer to the Magnitude Table -1 (For ex: If the coda is between $36-50$ seconds the magnitude is 2.0). Similarly, calculate epicentral distance and magnitude for all the earthquakes recorded on that Julian day. 


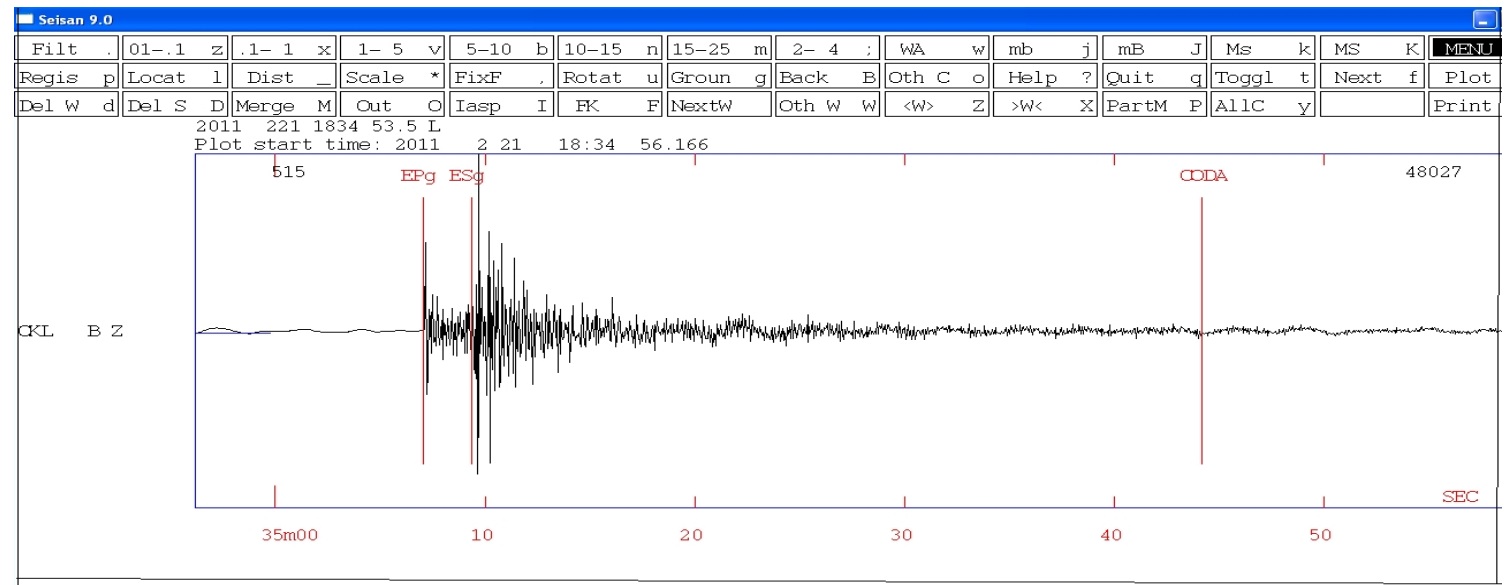

Figure 4. Single component seismogram of earthquake of M 2.0 recorded at Chikli seismograph station

Example: (As seen in the fig. 4 above)

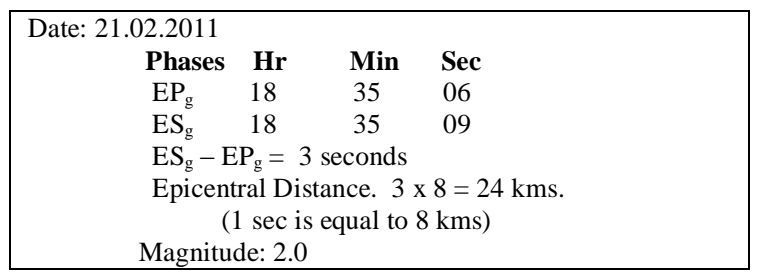

Table 1: Magnitude calculation sheet

\begin{tabular}{|c|c|}
\hline Coda Duration in Seconds (approx) & Magnitude (approx ) \\
\hline $1-10$ & 0.3 \\
\hline $11-20$ & 1.0 \\
\hline $21-35$ & 1.5 \\
\hline $36-50$ & 2.0 \\
\hline $51-80$ & 2.5 \\
\hline $81-105$ & 2.8 \\
\hline $106-125$ & 3.0 \\
\hline $126-165$ & 3.3 \\
\hline $166-200$ & 3.5 \\
\hline $200-215$ & 3.6 \\
\hline $216-235$ & 3.7 \\
\hline $236-250$ & 3.8 \\
\hline $251-280$ & 3.9 \\
\hline $281-305$ & 4.0 \\
\hline $306-335$ & 4.1 \\
\hline $336-365$ & 4.2 \\
\hline $366-399$ & 4.3 \\
\hline $400-435$ & 4.4 \\
\hline $436-475$ & 4.5 \\
\hline
\end{tabular}

Table 1: Clearly shows how to calculate CODA duration in seconds of recorded earthquake (coda is the end point of the recorded earthquake) and calculate magnitude while seeing the coda duration in seconds.

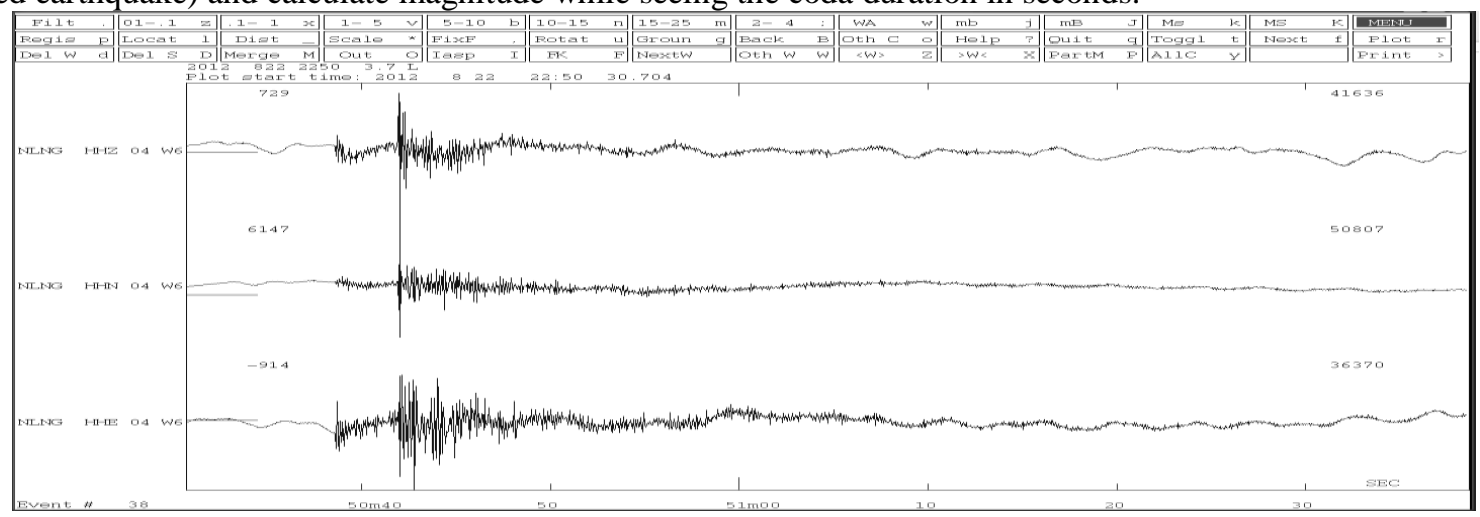

figure 5. 3-Component seismogram of earthquake of M 2.1 recorded at Nilanga seismograph station 


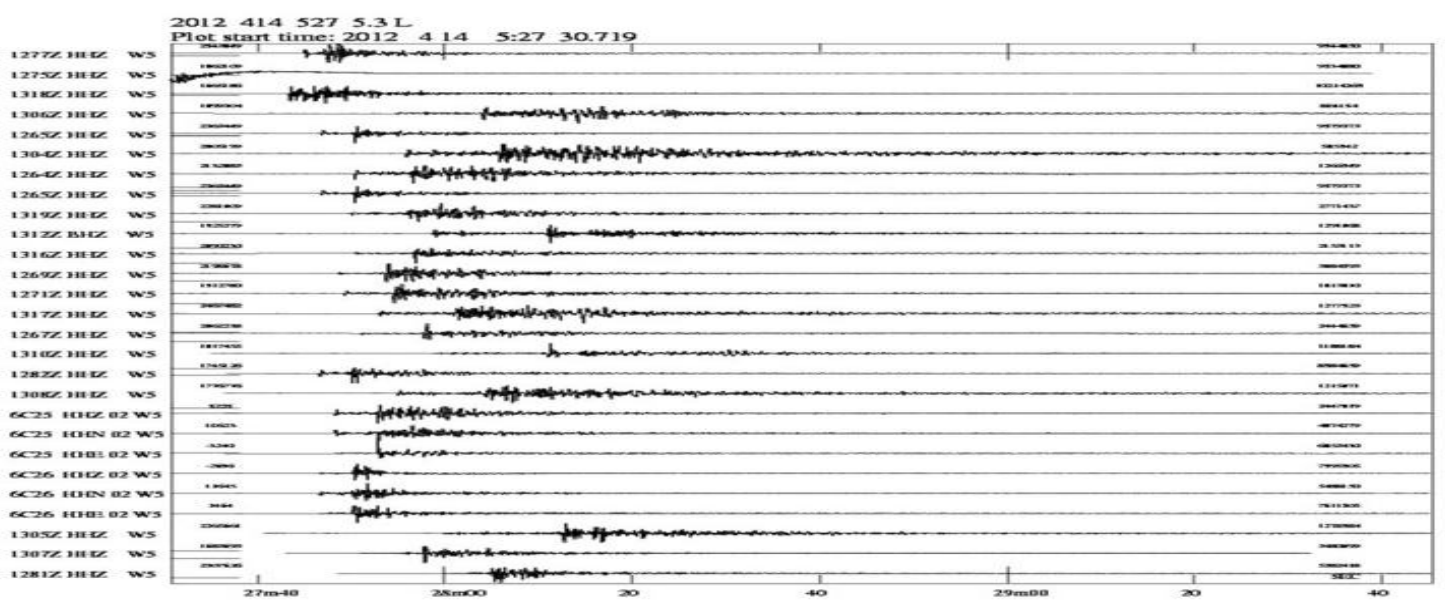

Figure 6. Earthquake waveform of April 14, 2014 event recorded by few stations of the network

Earthquakes recorded by educational seismograph (3-component seismogram) as shown in Fig.6 above.

Table 2: Training Programme conducted for teachers from different district of Western Maharashtra

\begin{tabular}{|c|c|c|c|}
\hline $\mathrm{s} / \mathrm{n}$ & Date & District & Number of teachers trained \\
\hline 1 & $22-24 \mathrm{feb}, 2011$ & Satara & 12 \\
\hline 2 & $13-15 \mathrm{Sept}, 2011$ & Sangli,Kholapur & 20 \\
\hline 3 & $20-22 \mathrm{Sept}, 2011$ & Ratnagiri,Raigad & 16 \\
\hline 4 & $23-25 \mathrm{Jan}, 2012$ & Nanded,Latur,Osmanabad & 19 \\
\hline 5 & $02-04$ May,2012 & Satara,Sangli,Ratnagiri & 16 \\
\hline
\end{tabular}

Table 2: indicate a training program conducted for all the teacher-in-charge of the earthquake labs has been organized at CSIR-National Geophysical Research Institute (NGRI), Hyderabad for a period of three days. The teachers are trained hand on practice in the operation of the educational seismograph, earthquake data retrieval and data analysis.

\section{Conclusion}

On the basis of the data available from all seismograph stations has been used for research purpose. The seismographs station setup was one of the important components of the mission mode programme, directed toward catalyzing creative approaches for earthquake hazard mitigation by developing rational bases in the minds of students for understanding the earthquake phenomena. The students are also motivated to take up a career in earth sciences. The seismograph station setup in secondary programme, So far, has helped in imparting training and creating awareness amongst more than 1, 00,000 students in NW and NE India [2] and about 2, 00,000 students are likely to be covered in next five years under this programme. It is also planned to strengthen these efforts and set up earthquake labs in other parts of India, via Gujarat and NE region. We feel these efforts will go a long way in dealing with adverse impact of earthquake hazard as well as providing inputs for research. The installation of seismograph in secondary schools also facilitates a low cost seismic network. The generated data can be used in evaluating the seismicity of the region concerned.

\section{Acknowledgments}

The authors are grateful to Dr Y J Bhaskar Rao, Acting Director, National Geophysical Research Institute, Hyderabad for according permission to publish this work.

[1]. http://www.guralp.com

\section{References}

[2]. Brijesh K bansal \& Mithila Verma, Education and awareness: A key to earthquake risk reduction, Journal Geological Society of India, Vol.80, 2012, 451-454.

[3]. A.Sateesh, G Suresh, R Vijayaraghavan, Satish Saha,Ans Sarma, PR Jitender, YVVBSN Murthy \& D Srinagesh, "Western India Schools Earthquake Lab Programme,’Technical Report No. NGRI-2014- SEISM-874, 2014, 1-25.

[4]. Seisan: The earthquake analysis software. Jens Havskov, Lars Ottemöller and Peter Voss. 